\title{
Work ability in midlife as a predictor of mortality and disability in later life: a 28-year prospective follow-up study
}

\author{
Mikaela B. von Bonsdorff PhD, Jorma Seitsamo PhD, Juhani Ilmarinen PhD, Clas-Håkan Nygård PhD, \\ Monika E. von Bonsdorff PhD, Taina Rantanen PhD
}

\begin{abstract}
Background: Poor work ability correlates with increased morbidity and early retirement from the workforce, but the association in old age is not known. We investigated work ability in midlife among white-collar and blue-collar employees as a predictor of mortality and disability 28 years later.
\end{abstract}

Methods: A total of 5971 occupationally active people aged $44-58$ years participated in the Finnish Longitudinal Study of Municipal Employees (FLAME) in 1981. Perceived work ability relative to lifetime best was categorized as excellent, moderate or poor. In 2009, the ability to perform activities of daily living was assessed among 2879 respondents $(71.0 \%$ of the survivors). Mortality data were available up to July 2009.

Results: At the 28-year follow-up, 1918 of the 5971 participants had died and 1403 had some form of disability. Rates of death per 1000 person-years among white-collar men were 7.7 for those with excellent work ability, 14.7 for those with moderate work ability and
23.5 for those with poor work ability. Among blue-collar men, the corresponding rates were 15.5, 20.2 and 25.3. In women, rates ranged between 6.3 and 10.6 per 1000 person-years. The age-adjusted hazard ratios (HRs) for mortality were two to three times higher among blue-collar male employees with lower work ability than among white-collar male employees with excellent work ability in midlife (i.e., the reference group). The odds of death or disability at follow-up compared with whitecollar workers with excellent work ability were highest among blue-collar employees with poor work ability in midlife (odds ratio [OR] 4.56, 95\% confidence interval [CI] 2.827.37 for men; OR 3.37, 95\% Cl 2.28-4.98 for women). Among the survivors, similar but slightly lower risks of disability 28 years later were found.

Interpretation: Perceived poor work ability in midlife was associated with accelerated deterioration in health and functioning and remains evident after 28 years of follow-up.
$\mathrm{P}$ rospective studies with a follow-up time stretching from midlife to old age have shown that lower socioeconomic status, as indicated by lower education level or occupational grade, predicts a decline in health and functioning in the working population..$^{1-4}$ This association is similar, if not more pronounced, in old age..$^{5-7}$

Higher levels of work-related mental and physical strain increase the risk of early retirement and predict a decline in health and an increase in mortality among the working population. ${ }^{3,8-15}$ However, the association between the demands of the work in conjunction with inadequate mental or physical resources (i.e., work ability $)^{16}$ and health and functioning in old age has not been studied. ${ }^{17}$ Using a population-based 28-year follow-up study involving middle-aged municipal employees, we investigated whether work ability in midlife predicts the risk of death and disability during old age among white-collar and blue-collar employees.

\section{Methods}

\section{Participants and design}

The Finnish Institute of Occupational Health's Finnish Longitudinal Study on Municipal Employees (FLAME) targeted 7344 individuals aged 44-58 years at baseline in $1981 .{ }^{18}$ The participants had been chosen at random from members of all municipal professions in Finland. The baseline cohort consisted of 6257 employees ( $44.7 \%$ men), for a response rate of $85.2 \%$. The first questionnaire, which explored work, health and lifestyle factors, was sent out in 1981, and follow-up data were collected in 1985, 1992, 1997 and 2009. Data on work ability were missing for 199 women and 87 men. The analyses in this study are based on the responses of 5971
Competing interests: None declared.

This article has been peer reviewed.

Correspondence to:

Dr. Mikaela B.

von Bonsdorff,

mikaela.vonbonsdorff

@jyu.fi

CMAJ 2011. DOI:10.1503 /cmaj.100713 
participants (45.4\% men) who answered the question on work ability at baseline, for a response rate of $81.3 \%$.

\section{Occupational group and work ability}

Occupational group was defined as the participants' position of employment at baseline. The 133 different job titles identified were clustered into 13 occupations based on an analysis of the jobs performed at the various places of work. ${ }^{19}$ Occupations were then further collapsed into blue-collar (e.g., installation, home care, cleaning and assistant nurse work) and white-collar (e.g., office, administrative, teaching and registered nurse work) classifications.

At baseline, work ability was determined as a subjective assessment of current work ability compared with a person's self-identified lifetime best (i.e., with the question "Assume that your work ability at its best has a value of 10 points. What score would you give your current work ability?"). This question is part of the seven-item Work Ability Index and captures most of the individual differences of the index,${ }^{20}$ which is why it was chosen for our analyses. The Work Ability Index was developed at the Finnish Institute of Occupational Health in the 1980s and has been validated against clinical data. ${ }^{21}$ It is based on a stress-strain concept and a balance concept, where individual resources correspond to job demand. ${ }^{22}$ Scores range from 0 (unable to work) to 10 (work ability at its best) and are categorized into excellent (scores 9-10, highest quartile), moderate (scores 7-8, two middle quartiles) and poor (scores $0-6$, lowest quartile) work ability (modified from Gould and colleagues). ${ }^{23}$

To account for any changes in work ability that may have occurred late in a person's career, we calculated the change in work ability scores from 1981 to 1992 (i.e., score in 1992 subtracted from score in 1981).

\section{Outcomes}

The study population was followed for mortality between Jan. 1, 1981, and July 31, 2009. Data were obtained from the Finnish National Population Register. Survival time was calculated as the number of days between the baseline examination and either death or the end of the follow-up period, whichever occurred first.

The Activities of Daily Living and Instrumental Activities of Daily Living questionnaires were used to assess disability at the 28-year follow-up in 2009. ${ }^{24,25}$ Data from 2879 participants (all of the respondents for whom data on disability were available at follow-up) were used in our analyses. Participants were asked about their ability to manage daily tasks. They were required to select their answers from the following possibilities: perform tasks without any difficulty, perform tasks with some difficulty, perform tasks with a lot of difficulty, require help to perform tasks and unable to perform tasks. Data were collected on the levels of difficulty encountered while performing the basic activities of daily living (i.e., feeding, bathing, dressing, toileting and transferring to and from bed), ${ }^{24}$ and more complex instrumental activities (i.e., preparing meals, doing laundry, shopping, coping with light housework, administering and taking medication, using the telephone and handling finances). ${ }^{25}$ Both scales are commonly used and are valid predictors of subsequent health and functioning among older people..$^{26,27}$ Test-retest reliability is high for both scales, ranging from $87 \%$ to $100 \% .{ }^{28}$ Using disability data from both scales, we created a dichotomized outcome of respondents with a disability 28 years later (people who encountered some degree of difficulty performing at least one of the basic or instrumental activities of daily living) versus respondents without a disability 28 years later.

Finally, using the disability and mortality data, we created a combined outcome of respondents who either had a disability or who had died versus respondents who were still alive and had no disability 28 years later.

\section{Baseline covariates}

Sociodemographic details included age, sex and marital status. Data concerning lifestyle habits such as smoking (never smoked, used to smoke or currently smokes), alcohol consumption (never, twice a month at most or at least once a week) and physical activity during the previous year (inactive, moderate activity no more than once a week or vigorous activity at least once a week) were also collected using the questionnaire. In addition, respondents were asked whether they had any illnesses or injuries that had been diagnosed or treated by a physician. We included musculoskeletal diseases (e.g., arthritis, degenerative diseases of the back and extremities), heart and circulatory diseases (e.g., hypertension and angina pectoris), respiratory diseases (e.g., chronic obstructive pulmonary disease and asthma) and metabolic diseases (e.g., diabetes and obesity) in the list of possible responses.

\section{Statistical analysis}

Results for men and women are presented separately because the interaction terms between sex and work ability, as well as between sex and occupational group, were statistically significant. The interaction terms for occupational status and 
work ability at baseline were also significant. To make the difference in risk levels visible, we created a six-category variable that combined information on occupational group and work ability: white-collar employee with excellent work ability (the reference group), moderate work ability or poor work ability, and blue-collar employee with excellent, moderate or poor work ability.

Mortality per 1000 person-years was calculated for each group. Hazard ratios (HRs) and 95\% confidence intervals (CIs) were estimated for mortality with Cox proportional-hazard regression models. No data on the work ability of the participants before baseline in 1981 were available, so we used the date of entry to the study cohort in the measurement of survival. Participants were included in the analyses until the date of their death or the end of follow-up, whichever came first. The odds ratios (ORs) and 95\% CIs for disability and the combined outcome of disability or death were calculated with logistic regression models.
Sensitivity analyses were conducted to account for possible bias due to dropout. We performed regression imputation for disability for people with missing data but who were alive in 2009 using the most recent data available (from either the 1997 or the 1992 data sets). Of the 1174 survivors with missing data, we were able to impute values for 597 people for disability and the combined outcome of disability or death. Data on chronic conditions, work ability and the sum score of functional ability (coping with heavy household chores, lifting and carrying more than $10 \mathrm{~kg}$, climbing three flights of stairs without resting, walking $2 \mathrm{~km}$ without resting and running $100 \mathrm{~m}$ without resting) were used for imputation.

\section{Results}

At the 28-year follow-up in 2009, 1918 (1197 men and 721 women) of the 5971 original participants had died, 2980 had survived and completed

\begin{tabular}{|c|c|c|c|c|c|c|c|c|}
\hline \multirow[b]{2}{*}{ Characteristic } & \multicolumn{4}{|c|}{ Work ability among white-collar employees } & \multicolumn{4}{|c|}{ Work ability among blue-collar employees } \\
\hline & $\begin{array}{l}\text { Excellent, } \\
n=247\end{array}$ & $\begin{array}{l}\text { Moderate, } \\
n=416\end{array}$ & $\begin{array}{l}\text { Poor, } \\
n=141\end{array}$ & $p$ value & $\begin{array}{l}\text { Excellent, } \\
n=344\end{array}$ & $\begin{array}{l}\text { Moderate, } \\
n=962\end{array}$ & $\begin{array}{l}\text { Poor, } \\
n=600\end{array}$ & $p$ value \\
\hline Age, yr, mean (SD) & $49.7(3.5)$ & $50.4(3.6)$ & $51.3(3.5)$ & $<0.001 *$ & $49.9(3.5)$ & $50.3(3.6)$ & $50.9(3.7)$ & $<0.001 *$ \\
\hline BMI, $\mathrm{kg} / \mathrm{m}^{2}$, mean (SD) & $24.2(3.2)$ & $24.9(3.4)$ & $25.0(3.8)$ & $<0.001 *$ & $25.5(3.4)$ & $25.6(3.4)$ & $26.1(3.8)$ & $0.189 *$ \\
\hline $\begin{array}{l}\text { Net family income over } \\
1700 € \text { per month, } \%\end{array}$ & 94.7 & 89.3 & 84.8 & $0.005 \dagger$ & 66.7 & 59.0 & 52.3 & $<0.001 \dagger$ \\
\hline $\begin{array}{l}\text { Began full-time work } \\
\text { before age } 18 \mathrm{yr}, \%\end{array}$ & 35.6 & 49.4 & 59.3 & $<0.001 \dagger$ & 78.4 & 81.6 & 86.9 & $0.002 \dagger$ \\
\hline Smoking status, $\%$ & & & & $<0.001 \dagger$ & & & & $<0.001 \dagger$ \\
\hline Never smoked & 45.1 & 36.8 & 31.2 & & 32.0 & 23.4 & 20.4 & \\
\hline Used to smoke & 43.5 & 42.4 & 39.7 & & 33.7 & 44.7 & 41.8 & \\
\hline Currently smokes & 11.4 & 20.8 & 29.1 & & 34.3 & 31.9 & 37.8 & \\
\hline Alcohol intake, \% & & & & $0.111 \dagger$ & & & & $0.207 \dagger$ \\
\hline None & 13.9 & 12.1 & 9.9 & & 13.2 & 11.2 & 12.2 & \\
\hline$\geq 2$ drinks/month & 64.8 & 67.0 & 58.9 & & 70.7 & 69.1 & 65.7 & \\
\hline$\geq 1$ drink/week & 21.3 & 20.9 & 31.2 & & 16.1 & 19.7 & 22.1 & \\
\hline Physical activity, $\%$ & & & & $<0.001 \dagger$ & & & & $<0.001 \dagger$ \\
\hline Very active & 68.6 & 51.5 & 45.0 & & 54.7 & 42.3 & 34.8 & \\
\hline Moderately active & 27.3 & 45.1 & 47.9 & & 36.2 & 47.5 & 50.5 & \\
\hline Inactive & 4.1 & 3.4 & 7.1 & & 9.1 & 10.2 & 14.7 & \\
\hline Musculoskeletal disease, $\%$ & 14.6 & 27.6 & 56.7 & $<0.001+$ & 17.2 & 36.0 & 60.3 & $<0.001 \dagger$ \\
\hline $\begin{array}{l}\text { Heart and circulatory } \\
\text { disease, } \%\end{array}$ & 10.1 & 21.9 & 41.1 & $<0.001 \dagger$ & 9.0 & 21.3 & 37.8 & $<0.001 \dagger$ \\
\hline Respiratory disease, \% & 4.5 & 12.0 & 19.1 & $<0.001 \dagger$ & 4.4 & 10.0 & 22.0 & $<0.001 \uparrow$ \\
\hline Metabolic disease, \% & 2.8 & 7.7 & 17.0 & $<0.001+$ & 2.9 & 8.0 & 12.8 & $<0.001 \dagger$ \\
\hline
\end{tabular}


the questionnaire (73.5\% of the survivors), and 1073 had survived but did not respond.

For most respondents $(66.0 \%)$, work ability was stable, with either no or a minor (1-point) change during the period from 1981 to 1992. The score increased by two points or more for $6.3 \%$ of respondents and decreased by two points or more for $27.7 \%$ of those surveyed.

Respondents were slightly younger (50.1 [standard deviation (SD) 3.4] v. 50.9 (3.6) years; $p<0.001)$, a greater proportion were white-collar employees $(46.1 \%$ v. $33.9 \%, p<0.001)$ and they more frequently reported excellent work ability at baseline $(30.5 \%$ v. $26.3 \%, p=0.001)$ than the surviving nonrespondents. The number of self-reported physician-diagnosed illnesses or injuries did not differ between respondents and nonrespondents (4.8 diagnoses, SD 2.1, $p=$ $0.14)$.

Tables 1 and 2 show the baseline health, socioeconomic status and lifestyle characteristics of the participants in midlife according to occu- pational group and work ability. Those who reported excellent work ability in midlife were slightly younger than those who reported moderate or poor work ability. Blue-collar employees were more likely than white-collar employees to have started full-time work before the age of 18 years. Employees with poor work ability had more chronic diseases than those with moderate or excellent work ability regardless of the occupational group to which they belonged. Bluecollar employees were more likely than whitecollar employees to report poor work ability at baseline (Table 3).

Mortality differed according to work ability in midlife in both occupational groups among men (log rank 87.48, 1 degree of freedom [df], $p<0.001$ ) and women (log rank 4.95, $1 \mathrm{df}, p=$ 0.026). Mortality was highest among those with poor work ability in midlife, intermediate among those with moderate work ability and lowest among those with excellent work ability for both white- and blue-collar employees. Higher and

\begin{tabular}{|c|c|c|c|c|c|c|c|c|}
\hline \multirow[b]{2}{*}{ Characteristic } & \multicolumn{4}{|c|}{ Work ability among white-collar employees } & \multicolumn{4}{|c|}{ Work ability among blue-collar employees } \\
\hline & $\begin{array}{l}\text { Excellent, } \\
n=574\end{array}$ & $\begin{array}{c}\text { Moderate, } \\
n=776\end{array}$ & $\begin{array}{l}\text { Poor, } \\
n=223\end{array}$ & $p$ value & $\begin{array}{c}\text { Excellent, } \\
n=389\end{array}$ & $\begin{array}{l}\text { Moderate, } \\
n=872\end{array}$ & $\begin{array}{l}\text { Poor, } \\
n=427\end{array}$ & $p$ value \\
\hline Age, yr, mean (SD) & $49.7(3.5)$ & $50.4(3.6)$ & $51.4(3.5)$ & $<0.001 *$ & $49.9(3.5)$ & $50.3(3.5)$ & $50.9(3.7)$ & $<0.001 *$ \\
\hline BMI, kg/m², mean (SD) & $24.9(2.6)$ & $26.0(2.8)$ & $26.2(3.4)$ & $<0.001 *$ & $26.1(3.1)$ & $26.4(3.2)$ & $26.4(3.2)$ & $0.019 *$ \\
\hline $\begin{array}{l}\text { Net family income over } \\
1700 € \text { per month, \% }\end{array}$ & 66.1 & 65.3 & 64.2 & $0.870 \dagger$ & 52.7 & 55.8 & 49.4 & $0.099 \dagger$ \\
\hline $\begin{array}{l}\text { Began full-time work } \\
\text { before age } 18 \mathrm{yr}, \%\end{array}$ & 19.5 & 20.7 & 24.9 & $0.244 \dagger$ & 40.5 & 42.6 & 50.2 & $0.011 \dagger$ \\
\hline Smoking status, \% & & & & $0.350 \dagger$ & & & & $0.341 \dagger$ \\
\hline Never smoked & 73.9 & 69.5 & 72.5 & & 80.5 & 81.2 & 77.4 & \\
\hline Used to smoke & 14.5 & 18.6 & 17.1 & & 8.8 & 9.8 & 10.0 & \\
\hline Currently smokes & 11.6 & 11.9 & 10.4 & & 10.6 & 9.0 & 12.6 & \\
\hline Alcohol intake, \% & & & & $0.049+$ & & & & $0.678 \dagger$ \\
\hline None & 36.5 & 38.3 & 43.7 & & 49.2 & 47.9 & 49.0 & \\
\hline$\geq 2$ drinks/month & 60.2 & 56.8 & 55.0 & & 47.9 & 50.0 & 49.5 & \\
\hline$\geq 1$ drink/week & 3.3 & 4.9 & 1.3 & & 2.9 & 2.1 & 1.5 & \\
\hline Physical activity, \% & & & & $<0.001 \dagger$ & & & & $<0.001 \dagger$ \\
\hline Very active & 59.1 & 50.1 & 43.6 & & 57.3 & 48.1 & 39.9 & \\
\hline Moderately active & 36.3 & 43.6 & 45.0 & & 36.1 & 42.2 & 49.0 & \\
\hline Inactive & 4.6 & 6.3 & 11.4 & & 6.6 & 9.7 & 11.1 & \\
\hline Musculoskeletal disease, \% & 17.9 & 40.5 & 60.5 & $<0.001 \dagger$ & 20.1 & 45.2 & 65.8 & $<0.001 \dagger$ \\
\hline $\begin{array}{l}\text { Heart and circulatory } \\
\text { disease, } \%\end{array}$ & 7.3 & 20.9 & 33.2 & $<0.001 \dagger$ & 13.9 & 23.4 & 29.5 & $<0.001 \dagger$ \\
\hline Respiratory disease, $\%$ & 4.4 & 12.5 & 19.7 & $<0.001 \dagger$ & 7.7 & 13.0 & 21.8 & $<0.001 \dagger$ \\
\hline Metabolic disease, \% & 5.1 & 11.9 & 20.2 & $<0.001 \dagger$ & 6.4 & 12.4 & 16.9 & $<0.001 \dagger$ \\
\hline
\end{tabular}


more pronounced differences in mortality were observed among men (Table 4).

Table 5 shows the hazard ratios for death and the odds ratios for death or disability and for disability. Mortality was higher among blue-collar men with lower work ability in midlife than among white-collar men who had reported excellent work ability in midlife. Mortality did not differ according to occupational group and work ability in midlife among women.

At the 28-year follow-up, 1529 participants had survived without a disability, and 3268 either had died or had some degree of disability. When compared with the reference group, the adjusted risk of death or disability at follow-up was highest among blue-collar employees with poor work ability at baseline (Table 5). In both occupational groups, the risk of death or disability at follow-up was threefold among men and twofold among women who had indicated moderate work ability in midlife compared with white-collar employees with excellent work ability in midlife.

Of the survivors at the 28-year follow-up, 1529 had no disability and 1350 had some degree of disability. The prevalence of disability according to occupational group and midlife work ability is shown in Table 6.

The adjusted odds of disability at the 28-year follow-up was highest among white- and bluecollar employees who had reported moderate and poor work ability in midlife compared with white-collar employees who had reported excellent work ability in midlife (Table 5). There was a gradient increase in the risk of disability across both occupational groups: those with poor work ability in midlife had the highest risk, those with moderate work ability had an intermediate risk and those with excellent work ability had the lowest risk. Work ability and age explained about $10 \%$ of the variance in disability and $15 \%$ of the variance in the combined outcome of disability or death in the logistic regression models.

Results of the sensitivity analyses that included imputed data for the combined outcome of disability or death and for disability were similar to those of the main analyses (data not shown).

\section{Interpretation}

We found that work ability in midlife predicted decline in health and functioning among men and women during the 28-year follow-up even after adjustment for health and lifestyle factors. The risks showed similar gradients among blueand white-collar employees, but risk of death was generally higher among blue-collar employees. The fact that work ability in midlife predicted disability almost three decades later despite the competing risk of death indicates that work ability may be considered as an early predictor of the risk of disability in old age.

Table 3: Work ability in midlife according to occupational group for men and women

\begin{tabular}{|c|c|c|c|c|}
\hline \multirow[b]{2}{*}{ Work ability } & \multicolumn{2}{|c|}{ Men, \% (95\% CI) } & \multicolumn{2}{|c|}{ Women, \% (95\% Cl) } \\
\hline & White collar & Blue collar & White collar & Blue collar \\
\hline Excellent & $30.7(25.0-36.4)$ & $18.0(13.9-22.1)$ & $36.5(32.6-40.4)$ & $23.0(18.8-27.1)$ \\
\hline Moderate & $51.8(47.0-56.6)$ & $50.5(47.3-53.7)$ & $49.3(45.8-52.9)$ & $51.7(48.4-55.0)$ \\
\hline Poor & $17.5(11.2-23.8)$ & $31.5(27.8-35.2)$ & $(9.6-18.8)$ & $25.3(21.2-29.4)$ \\
\hline
\end{tabular}

Note: $\mathrm{Cl}=$ confidence interval.

\begin{tabular}{|c|c|c|c|c|}
\hline \multirow[b]{2}{*}{ Work ability } & \multicolumn{2}{|c|}{ Men, \% $(95 \% \mathrm{Cl})$} & \multicolumn{2}{|c|}{ Women, \% (95\% CI) } \\
\hline & White collar & Blue collar & White collar & Blue collar \\
\hline Excellent & $7.7(5.6-9.9)$ & $15.5(12.9-18.3)$ & $6.3(5.1-7.7)$ & $8.2(6.5-10.0)$ \\
\hline Moderate & $14.7(12.4-17.2)$ & $20.2(18.4-22.2)$ & $8.8(7.6-10.2)$ & $7.8(6.6-9.0)$ \\
\hline Poor & $23.5(18.3-29.3)$ & $25.3(22.6-28.1)$ & $9.8(7.4-12.6)$ & $10.6(8.7-12.6)$ \\
\hline$p$ value & $<0.001 *$ & $<0.001 *$ & $0.006^{*}$ & $0.022 *$ \\
\hline
\end{tabular}


Earlier studies showed that lower professional grades were associated with an increased risk of morbidity, mortality and disability in old age.,4-6,29 In our study, we observed that the risks of disability and mortality were higher among blue-collar than among white-collar employees at a given level of work ability. However, baseline prevalence of poor work ability was double among the blue-collar employees, which might explain the increased risk of declining health and functioning among blue-collar occupations. These findings require confirmation with further studies.
Although mental and physical work strain and work ability are related, they are distinct concepts. A high degree of work-related physical and mental strain, together with inadequate resources to cope with such strain, cause declined work ability. ${ }^{30}$ Previous prospective studies reported on the association of higher work-related mental and physical strain and declining health and increased mortality among members of the workforce. , $8,9,14,15$ The association between work-related mental and physical strain and disability in old age has been studied in-

\begin{tabular}{|c|c|c|c|c|c|c|}
\hline \multirow[b]{2}{*}{ Work ability } & \multicolumn{2}{|c|}{ Death, HR $(95 \% \mathrm{CI})$ * } & \multicolumn{2}{|c|}{ Disability or death, OR $(95 \% \mathrm{Cl}) \dagger$} & \multicolumn{2}{|c|}{ Disability, OR $(95 \% \mathrm{Cl}) \neq$} \\
\hline & Model 1§ & Model 2ף & Model $1 \S$ & Model 2ף & Model 1§ & Model 2ף \\
\hline \multicolumn{7}{|l|}{ Men } \\
\hline \multicolumn{7}{|l|}{ White collar } \\
\hline Excellent & 1.00 & 1.00 & 1.00 & 1.00 & 1.00 & 1.00 \\
\hline Moderate & $1.82(1.33-2.50)$ & $1.48(1.04-2.11)$ & $2.36(1.63-3.42)$ & $2.11(1.42-3.15)$ & $1.98(1.30-3.01)$ & $1.96(1.25-3.07)$ \\
\hline Poor & $2.69(1.88-3.86)$ & $1.84(1.20-2.82)$ & $4.50(2.46-8.22)$ & $2.98(1.54-5.78)$ & $2.79(1.41-5.53)$ & $2.67(1.29-5.54)$ \\
\hline \multicolumn{7}{|l|}{ Blue collar } \\
\hline Excellent & $2.29(1.66-3.17)$ & $1.75(1.22-2.51)$ & $2.73(1.84-4.05)$ & $2.16(1.40-3.32)$ & $1.59(1.00-2.54)$ & $1.50(0.90-2.47)$ \\
\hline Moderate & $2.59(1.94-3.45)$ & $2.02(1.46-2.80)$ & $4.15(2.97-5.81)$ & $3.03(2.09-4.40)$ & $2.39(1.62-3.52)$ & $2.21(1.45-3.37)$ \\
\hline Poor & $3.18(2.37-4.28)$ & $2.17(1.54-3.07)$ & $5.95(4.00-8.86)$ & $4.56(2.82-7.37)$ & $3.16(2.01-4.96)$ & $3.45(2.03-5.88)$ \\
\hline \multicolumn{7}{|l|}{ Women } \\
\hline \multicolumn{7}{|l|}{ White collar } \\
\hline Excellent & 1.00 & 1.00 & 1.00 & 1.00 & 1.00 & 1.00 \\
\hline Moderate & $1.28(1.00-1.64)$ & $1.13(0.86-1.49)$ & $1.95(1.51-2.52)$ & $1.67(1.26-2.22)$ & $2.04(1.50-2.79)$ & $1.89(1.35-2.65)$ \\
\hline Poor & $1.29(0.93-1.79)$ & $1.24(0.85-1.80)$ & $2.47(1.69-3.62)$ & $2.45(1.57-3.82)$ & $2.86(1.84-4.43)$ & $2.69(1.62-4.45)$ \\
\hline \multicolumn{7}{|l|}{ Blue collar } \\
\hline Excellent & $1.30(0.97-1.74)$ & $1.09(0.77-1.52)$ & $1.52(1.12-2.07)$ & $1.39(0.99-1.95)$ & $1.40(0.96-2.05)$ & $1.49(0.99-2.24)$ \\
\hline Moderate & $1.14(0.89-1.46)$ & $1.12(0.85-1.48)$ & $2.14(1.66-2.76)$ & $1.82(1.37-2.42)$ & $2.41(1.78-3.26)$ & $2.10(1.50-2.95)$ \\
\hline Poor & $1.44(1.10-1.89)$ & $1.36(0.98-1.89)$ & $3.80(2.74-5.27)$ & $3.37(2.28-4.98)$ & $3.91(2.68-5.70)$ & $3.62(2.32-5.66)$ \\
\hline \multicolumn{7}{|c|}{$\begin{array}{l}\text { Note: } \mathrm{Cl}=\text { confidence interval, } \mathrm{HR}=\text { hazard ratio, } \mathrm{OR}=\text { odds ratio. } \\
\text { *Analyzed by Cox proportional hazards model ( } 2710 \text { men, } 3261 \text { women). } \\
\text { tAnalyzed by logistic regression ( } 2292 \text { men, } 2558 \text { women). } \\
\text { †Analyzed by logistic regression (1060 men, } 1798 \text { women). } \\
\text { §Model } 1 \text { adjusted for age. } \\
\text { ๆModel } 2 \text { adjusted for age, change in work ability from } 1981 \text { to } 1992, \text { marital status, alcohol intake, smoking, exercise and major chronic diseases. }\end{array}$} \\
\hline
\end{tabular}

Table 6: Prevalence of disability according to occupational group and work ability at the 28-year follow-up

\begin{tabular}{|c|c|c|c|c|c|c|c|c|}
\hline \multirow[b]{2}{*}{ Work ability } & \multicolumn{4}{|c|}{ Men, \% $(95 \% \mathrm{Cl})^{*}$} & \multicolumn{4}{|c|}{ Women, \% $(95 \% \mathrm{CI})$ * } \\
\hline & $n / N$ & White collar & $n / N$ & Blue collar & $n / N$ & White collar & $n / N$ & Blue collar \\
\hline Excellent & $164 / 247$ & $39.0(31.5-46.5)$ & $135 / 344$ & $48.9(44.6-53.2)$ & $366 / 574$ & $25.1 \quad(22.8-27.4)$ & $211 / 389$ & $31.8(28.6-35.0)$ \\
\hline Moderate & 212/416 & $57.1(53.7-60.5)$ & $342 / 962$ & $61.7(59.1-64.3)$ & 433/776 & $42.0 \quad(39.6-44.4)$ & $476 / 872$ & $45.7(43.4-48.0)$ \\
\hline Poor & $52 / 141$ & $67.3(60.6-74.0)$ & $172 / 600$ & $68.0(64.4-71.6)$ & $120 / 223$ & 52.5 (47.9-57.1) & $196 / 427$ & $58.7(55.2-62.2)$ \\
\hline
\end{tabular}


frequently, and the results are inconsistent. ${ }^{31}$ Consequently, our results parallel previous findings and expand on them because we were able to investigate disability as an outcome. We were also able to verify the findings in old age and examine work ability as a predictor among employees working in a wide variety of occupations.

The differences in survival rates between men and women were also obvious in our study. When studying disability in old age, it is important to consider mortality, as it is a competing risk for disability. This is particularly true among men but less so among women. In our study, work ability was more strongly associated with disability risk among women; among men, work ability was more strongly associated with mortality. The influence of the competing risk of mortality is clearly shown in our analysis of the combined outcome of disability or death at follow-up: the risk was much higher among men than among women. Among women, the risk of disability or death did not materially differ from the risk of disability. Earlier studies have shown that the higher prevalence of disability among women is not actually due to higher incidence rates but rather to longer duration of disability as a result of lower mortality. ${ }^{32}$

\section{Strengths and limitations}

One of the strengths of this study is the long prospective follow-up in a large populationbased data set respresenting a wide variety of municipal professions. Using such a relatively large data set, we were able to investigate disability as an outcome in old age, which is an important indicator of public health in a growing elderly population. The dates of death were derived from the national register and not from obituaries or information from next-of-kin or other sources.

A potential limitation of the analysis is selective dropout from the study. The healthy worker survivor effect is an ongoing process in which those who stay in a profession tend to be healthier than those who leave employment. ${ }^{33}$ Those from blue-collar occupations were more likely than white-collar occupations to drop out or have missing data later on. This could have resulted in an underestimation of the predictive value of work ability within occupational groups.

Data on disability were not available at baseline. However, most middle-aged people who were occupationally active in Finland in the 1980s did not experience difficulties with basic activities of daily living, ${ }^{34}$ so we are confident that a decline in work ability preceded disability in old age. Our findings are applicable to West- ern countries, although the results should be verified in countries that have different labour and welfare policies. Caution must be taken when generalizing the results at the population level because people in occupational groups tend to be healthier than the overall population, which includes people who are not in the workforce. Although the participants in this study worked in the public sector, the results can be generalized to the private sector as well in countries like Finland where labour legislation applies equally to both sectors.

\section{Conclusion}

Perceived work ability in midlife was associated with mortality and disability in old age among blue-collar and white-collar employees. It is plausible that a person's capacity to perform activities in relation to the demands posed by their age-appropriate role in society tracks through decades. The current work ability of middle-aged employees could therefore be considered as an early predictor of functioning in old age.

\section{References}

1. Marmot MG, Smith GD. Health inequalities among British civil servants: the Whitehall II study. Lancet 1991;337:1387-93.

2. Davey Smith G, Hart C, Hole D, et al. Education and occupational social class: Which is the more important indicator of mortality risk? J Epidemiol Community Health 1998;52:153-60.

3. Sacker A, Bartley MJ, Frith D, et al. The relationship between job strain and coronary heart disease: evidence from an English sample of the working male population. Psychol Med 2001; 31:279-90.

4. Huisman M, Kunst AE, Bopp M, et al. Educational inequalities in cause-specific mortality in middle-aged and older men and women in eight western European countries. Lancet 2005; 365:493-500.

5. Breeze E, Fletcher AE, Leon DA, et al. Do socio-economic disadvantages persist into old age? Self-reported morbidity in a 20 year follow-up of the Whitehall Study. Am J Public Health 2001;91:277-83.

6. Ebrahim S, Papacosta O, Wannamethee G, et al. Social inequalities and disability in older men: prospective findings from the British Regional Heart Study. Soc Sci Med 2004;59:2109-20.

7. Chandola T, Ferrie J, Sacker A, et al. Social inequalities in selfreported health in early old age: follow-up of prospective cohort study. BMJ 2007;334:990.

8. Johnson JV, Hall EM, Theorell T. Combined effects of job strain and social isolation on cardiovascular disease morbidity and mortality in a random sample of Swedish male working population. Scand J Work Environ Health 1989;15:271-9.

9. Marmot MG, Bosma H, Hemingway H, et al. Contribution of job control and other risk factors to social variations in coronary heart disease incidence. Lancet 1997;350:235-9.

10. Bosma H, Marmot MG, Hemingway $\mathrm{H}$, et al. Low job control and risk of coronary heart disease in Whitehall II (prospective cohort) study. BMJ 1997;314:558-65.

11. Krause N, Lynch J, Kaplan GA, et al. Predictors of disability retirement. Scand J Work Environ Health 1997;23:403-13.

12. Kivimäki M, Leino-Arjas $\mathrm{P}$, Luukkonen $\mathrm{R}$, et al. Work stress and risk of cardiovascular mortality: prospective cohort study of industrial employees. BMJ 2002;325:857.

13. Laine S, Gimeno D, Viratanen M, et al. Job strain as a predictor of disability: the Finnish public sector study. J Epidemiol Community Health 2009;63:24-30.

14. Amick BC, McDonough P, Chang H, et al. Relationship between all-cause mortality and cumulative working life course psychosocial and physical exposures in the United States labor market from 1968 to 1992. Psychosom Med 2002;64:370-81.

15. Bourgkard E, Wild P, Massin N, et al. Association of physical 
job demands, smoking and alcohol abuse with subsequent premature mortality: a 9-year follow-up population-based study. J Occup Health 2008;50:31-40.

16. Ilmarinen J. Work ability - a comprehensive concept for occupational health research and prevention. Scand $J$ Work Environ Health 2009;35:1-5.

17. Feldt T, Hyvonen K, Makikangas A, et al. Development trajectories of Finnish managers' work ability over a 10-year followup period. Scand J Work Environ Health 2009;35:37-47.

18. Ilmarinen J, Tuomi K, Eskelinen L, et al. Background and objectives of the Finnish research project on aging workers in municipal occupations. Scand J Work Environ Health 1991; 17(Suppl 1):7-11.

19. Ilmarinen J, Suurnakki T, Nygard CH, et al. Classification of municipal occupations. Scand J Work Environ Health 1991; 17(Suppl 1):12-29.

20. Tuomi K, Ilmarinen J, Eskelinen L, et al. Prevalence and incidence rates of diseases and work ability in different work categories of municipal occupations. Scand J Work Environ Health 1991;17(Suppl 1):67-74.

21. Eskelinen L, Kohvakka A, Merisalo T, et al. Relationship between the self-assessment and clinical assessment of health status and work ability. Scand J Work Environ Health 1991; 17(Suppl 1):40-7.

22. Rutenfranz J. Arbeitzmedizinische aspekte des stressproblems In: Nitsh JR, editor. Theorien, untersuchungen, massnahmen. Bern (Switzerland): Verlag Hans Huber; 1981. p. 379-90.

23. Gould R, Koskinen S, Seitsamo J, et al. Data and methods. In: Gould R, Ilmarinen J, Järvisalo J, et al., editors. Dimensions of work ability. Results from the Health 2000 Survey. Helsinki (Finland): Finnish Centre for Pensions; 2008. p. 25-34.

24. Katz S, Ford AB, Moskowitz RW, et al. Studies of illness in the aged. The index of ADL: a standardized measure of biological and psychosocial function. JAMA 1963;185:914-9.

25. Lawton MP, Brody EM. Assessment of older people: selfmaintaining and instrumental activities of daily living. Gerontologist 1969; 9:179-86.

26. Gaugler JE, Duval S, Anderson KA, et al. Predicting nursing home admission in the US: a meta-analysis. BMC Geriatr 2007;7:13.

27. Miller EA, Weissert WG. Predicting elderly people's risk for nursing home placement, hospitalization, functional impairment, and mortality: a synthesis. Med Care Res Rev 2000;57:259-97.

28. Wang CY, Sheu CF, Protas E. Construct validity and physical performance of older adults in different hierarchical physical- disability levels. J Aging Phys Act 2007; 15:75-89.

29. Li CY, Wu SC, Wen SW. Longest held occupation in a lifetime and risk of disability in activities of daily living. Occup Environ Med 2000;57:550-4

30. Tuomi K, Ilmarinen J, Klockars M, et al. Finnish research project on aging workers in 1981-1992. Scand J Work Environ Health 1997;23(Suppl 1):7-11.

31. Britton A, Shipley M, Singh-Manoux A, et al. Successful aging: the contribution of early-life and midlife risk factor. J Am Geriatr Soc 2008;56:1098-105.

32. Leveille SG, Guralnik JM, Ferrucci L, et al. Aging successfully until death in old age: opportunities for increasing active life expectancy. Am J Epidemiol 1999;149:654-64.

33. Wunsch G, Duchene J, Thiltges E, et al. Socio-economic differences in mortality. A life course approach. Eur J Popul 1996; 12:167-85.

34. Sauli H, Ahola A, Lahelma E, et al. Elinolot numeroina. Vuoden 1986 elinolotutkimus. [Living conditions in numbers. The living conditions research in 1986]. Finnish official statistics 1989. Helsinki (Finland): Statistics Finland; 1989.

Affiliations: From the Gerontology Research Centre (M.B. von Bonsdorff, M.E. von Bonsdorff, Rantanen), Department of Health Sciences, University of Jyväskylä, Jyväskylä, Finland; the Finnish Institute of Occupational Health (Seitsamo, Ilmarinen, M.E. von Bonsdorff), Helsinki, Finland; and the Tampere School of Public Health (Nygård), University of Tampere, Tampere, Finland

Contributors: Juhani Ilmarinen, Clas-Håkan Nygård, Jorma Seitsamo and Taina Rantanen contributed substantially to the conception and design of the study. Jorma Seitsamo, Monika von Bonsdorff and Mikaela von Bonsdorff contributed to data collection. Mikaela von Bonsdorff and Taina Rantanen analyzed and interpreted the data and drafted the manuscript. All of the authors critically revised the article and gave their final approval of the version submitted for publication.

Funding: The study was funded by the Academy of Finland.

Acknowledgement: The authors thank Markku Kauppinen for providing assistance with the statistics. 